\title{
Specific wear on the rake face made of sintered carbide cutting edge during milling of laminated wood
}

\author{
Bolesław Porankiewicz • Karol Jóźwiak • \\ Daria Wieczorek · Ireneusz Idzikowski
}

Received: 11 March 2014/Published online: 31 October 2014

(C) The Author(s) 2014. This article is published with open access at Springerlink.com

\begin{abstract}
An attempt to assess recesses on the rake face after milling wood laminated with polyvinyl acetate (PVA) based glue is presented. Several analytical methods were employed to explain tribo chemical corrosion reactions (TCCR) leading to formation of specific form of wear on the rake face. By means of thermal gravimetric analysis it was confirmed that cobalt and tungsten carbide-main components of sintered carbide cutting edge-were subjected to intensive TCCR. Although an increase in thermal stability of the PVA based glue after modification was evidenced, high temperature degradation of the glue to acetic acid was probably the primary source of TCCR. Catastrophic wear of the cemented carbide cutting edge was also evidenced as the final state of continuous deepening of the recess on the rake face near the cutting edge.
\end{abstract}

\section{Introduction}

Until recently it was thought that the polyvinyl acetate (PVA) - based adhesives used for gluing wood do not accelerate wear of cutting edge during the machining process. This point of view came rather from the fact that

B. Porankiewicz ( $\square)$

Poznań University of Technology, Poznań, Poland

e-mail: poranek@amu.edu.pl

K. Jóźwiak

Institute of Aviation, Warsaw, Poland

D. Wieczorek

Poznań University of Economics, Poznań, Poland

I. Idzikowski

Wooden Doors and Stairs “Kornik", Tarnowo Podgórne, Poland
PVA based adhesives have widely been used as assembly glue in the past but not for industrial production of laminated wood. Development of PVA — based adhesives made in recent years and aimed at increasing resistance to water encouraged engineers to the widespread use of PVA based adhesives also for the production of laminated wood components for indoor use. One of the reasons for the direction of technology of laminated wood products was the cost and technological parameters of PVA-based adhesives. It would seem that modern, advanced materials for tools allow for choosing material which ensures long lifetime of cutting edge during machining of wood laminated with PVA based glue at an affordable price. An attempt using high speed steel (HSS) resulted in significant shortening of the tool's lifetime. A use of the HSS cutting tools for solid wood of Scots pine milling brings good effects. In this case, change in the length of the blade rounding up of the cutting edge can be observed. On a flat part of the rake face near the edge, measurable signs of wear were not reported (Grube 1967; Klamecki 1967; Porankiewicz 2003b; Staniszewski and Porankiewicz 1978). The wear of the cutting edge of HSS is similar to the one reported for sintered carbide. The use of cemented carbide might give even better results, however, large accidental chipping greatly reduces the efficiency (Cristóvão et al. 2009, 2011; Grube 1967; Klamecki 1967; Porankiewicz 2003a; Staniszewski and Porankiewicz 1978). The use of cemented carbide for milling of wood laminated with PVA based glue revealed a previously unknown form of blade wear.

The purpose of the present study was to identify the form of wear of the cemented carbide cutting edge during milling of wood glued with PVA based adhesive and to try to understand the wear mechanisms involved in this process. 
Fig. 1 Milling of laminated and unglued wood: $I$ notch; II, III longitudinal; $a, b, c$ blades tested; $d$ blade for groove; asterisk glue joint; cutting layer is dotted
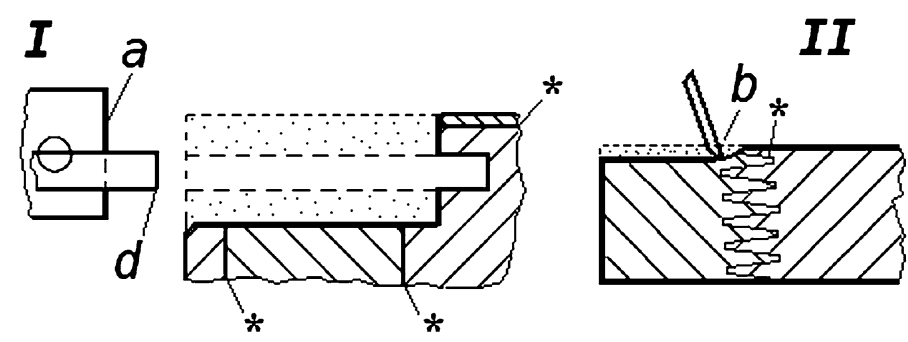

III

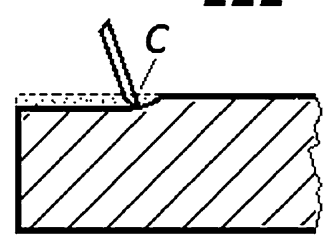

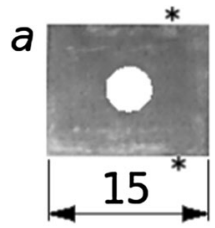
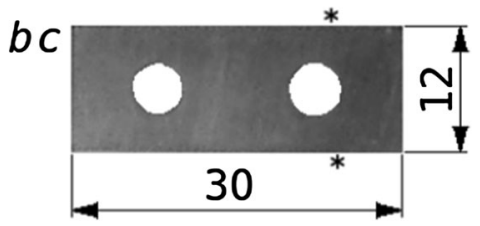

Fig. 2 Cutting blade turnover inserts: $a$ for notch milling; $b, c$ for longitudinal milling of the surface; asterisk cutting edges

\section{Materials and methods}

Notch milling (Fig. 1a) and longitudinal surface milling (Fig. 1b, c) of Scots pine (Pinus silvestris) laminated wood was carried out on a SCM Superset NT milling centre, in Doors and Stairs "Kornik", in Tarnowo Podgórne, Poland, with the following parameters:

- Rotational speed of the tool $n=6,000 \mathrm{~min}^{-1}$,

- Cutting speed $v_{c}=50 \mathrm{~m} / \mathrm{s}$,

- Feed speed $v_{f}=12 \mathrm{~m} / \mathrm{min}$,

- Total cutting path $L_{s}=214,890 \mathrm{~m}$,

- Total feed path $L_{f}=6,000 \mathrm{~m}$,

- Tool diameter $D_{s}=160 \mathrm{~mm}$,

- Blades number $z=3$,

- Bevel angle $\lambda_{p}=0^{\circ}$,

- Cutting depth $a: c_{d}=30 \mathrm{~mm}$, and $b, c: c_{d}=2 \mathrm{~mm}$,

- Rake angle: $\gamma_{f}=23^{\circ}$,

- Wedge angle: $\beta_{f}=55^{\circ}$,

- Feed rate per 1 edge $f_{z}=0.667 \mathrm{~mm}$,

- Blades construction (Fig. 2): mechanical fixation, rectangular turnover inserts, with dimensions $a=15 \times 12 \times 1.5 \mathrm{~mm} ; b, c=30 \times 12 \times 1.5 \mathrm{~mm}$,

- Material of the blades edge: cemented carbide type KCr08 (according to Ceratizit), with the binder: $\mathrm{Co}+\mathrm{Ni} 4.4 \%$, other $0.35 \%$.

Observations of worn cutting edges were performed to determine the topography of wearing zone using a EVO25 scanning electron microscope (SEM) manufactured by Zeiss and an VHX-600 optical digital microscope (DOM) manufactured by Keyence equipped with a digital image acquisition system.
To determine the chemical composition of deposits in the worn zone of the cutting edge semi-quantitative energy dispersive spectrometry (EDS) was applied. Quantitative measurement of worn cutting edge parameters of insert $a$ was carried out using a profilometer ME 10, manufactured by Zeiss.

Wear test for blade $a$ was carried out on Scots pine wood laminated with PVA-based adhesive, having water resistance class D3, at $9 \%$ moisture content.

Machining (Fig. 1) test was performed at a temperature of $20{ }^{\circ} \mathrm{C}$ for $24 \mathrm{~h}$ after gluing. For blade $b$, the longitudinal wedge connections of elements of Scots pine wood, repeat at approximately every $1,000 \mathrm{~mm}$, whereby the cutting was subjected to about 6,000 glued connections. For these connections the same PVA-based adhesive was used. For comparison, the blade $c$ worn during cutting of unglued Scots pine has also been subjected to observation.

The TGA analysis was performed using a Shimadzu TGA-50 apparatus in order to check the possibility of the occurrence of TCCR of the tool material during cutting edge wear process under the examined conditions.

Powdered components of the cutting edge material and the cured adhesive were analyzed according to a published method (Porankiewicz 2002; Porankiewicz and Chamot 2005).

\section{Results and discussion}

In Figs. 3, 4 and 5, the DOM images of the cutting edge wearing zone are presented from the rake face site. Clearly visible in Fig. 3 the recess form of the worn zone, is an unexpected form of wood cutting tool dulling. Excessively large recess on the rake face in some places resulted from chipping, which determined the need to replace the blades.

In the area of intense wear, a very different mosaic of corrosion was observed (Figs. 3, 4 and 5).

In case of blade $a$, this worn zone has an average width of $177 \mu \mathrm{m}$. In the case of blade $b$ the intense wear zone is narrower, on average $125 \mu \mathrm{m}$, because the contact feed length with the glue joint was only $2 \%$ of the total feed length for blade $a$. Apparent lack of a repetition of the 

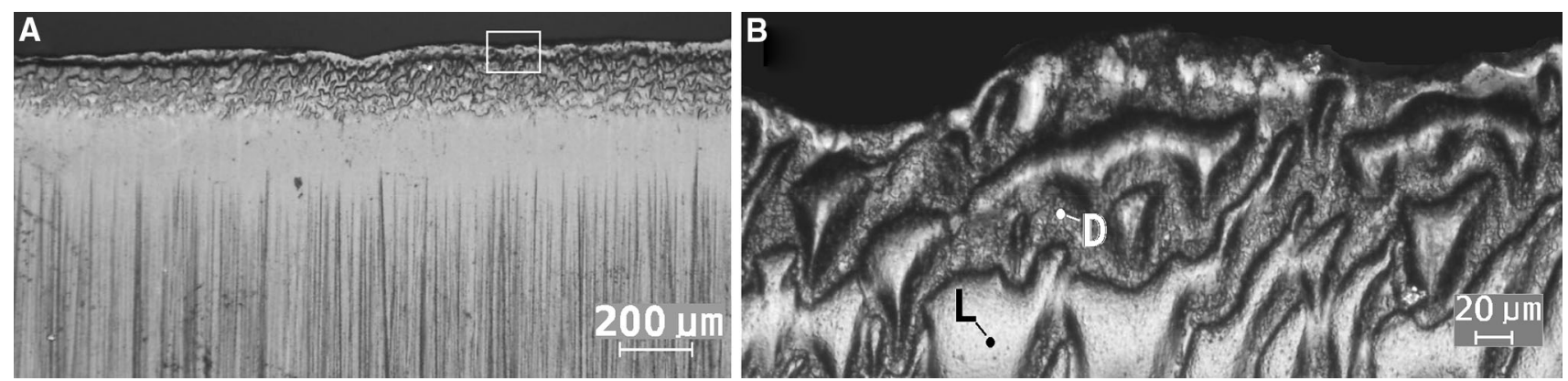

Fig. 3 Blade $a$ cutting edge worn zone from rake face site, the DOM sites are presented; a overview; $\mathbf{b}$ magnification of rectangle area; $L$ lighter area; $D$ darker area

Fig. 4 Blade $b$ cutting edge worn zone from rake face site, the DOM site is presented

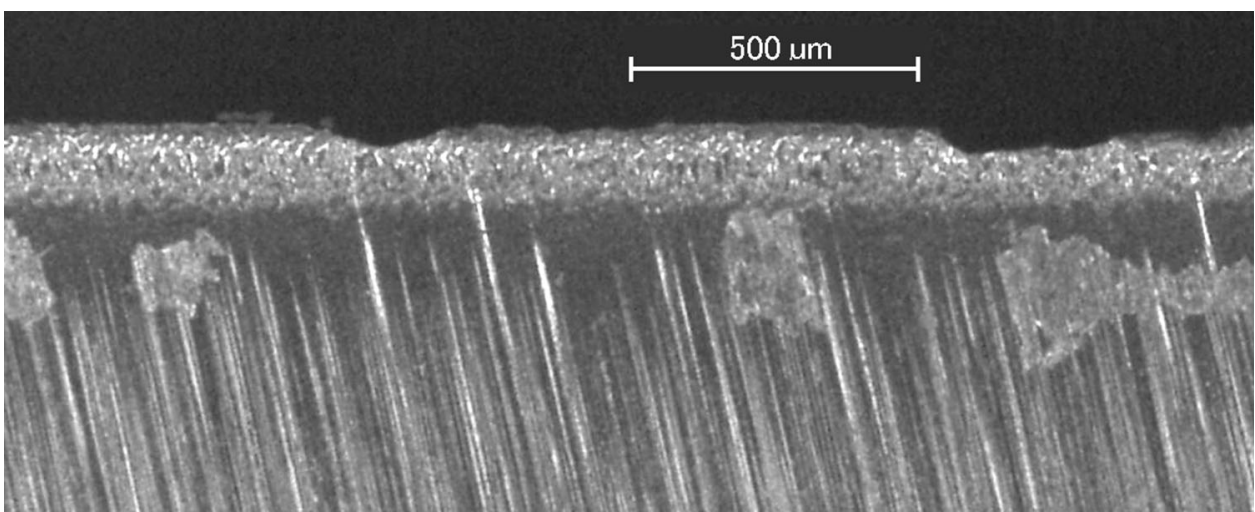

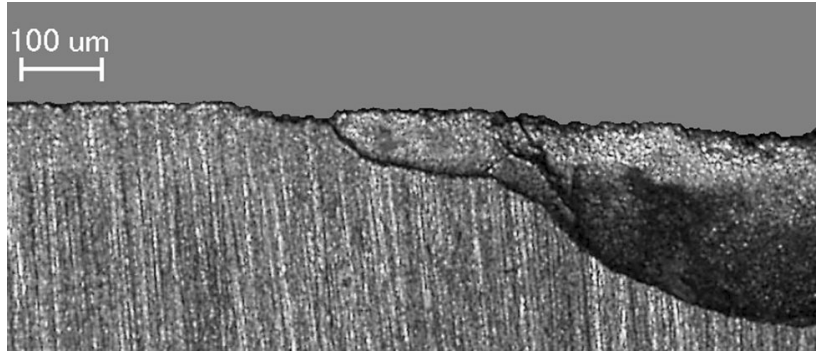

Fig. $5 \mathrm{KCr} 08$ cutting edge worn zone (blade $c$ ) after milling of not laminated solid wood, the DOM site is presented

corrosion mosaic sequence, consisting of elevation, lighter areas (L, Fig. 3b) and cavities, darker areas (D, Fig. 3b) can be seen in Fig. 3, therefore in some places the elevations are broader than the cavities, as well as in other places the situation is reversed.

The elevation width (Fig. 3b) at the widest point reaches $60 \mu \mathrm{m}$. Figure 3a illustrating the wear zone of blade $a$ shows that the corrosion mosaic ends at the polished surface, where grinding scratches are not visible. This observation can be explained by too little pressure of a chip on the rake surface, starting at a certain distance from the cutting edge.

The polished zone, shown in Fig. 3a, has a width of about $200 \mu \mathrm{m}$. It should also be noted that in the area of polished surface without visible grinding scratches, intense TCCR needed also to take place that led to the removal of layers of super-hard material of cemented carbide with a thickness greater than the depth of the deepest grinding scratches. So vast and deep polishing of the rake face (Fig. 3a) was not observed after cutting of unglued solid wood with the use of dull cemented carbide cutting edge (Fig. 5) (Grube 1967; Staniszewski and Porankiewicz 1978). Another characteristic zone of wear concerns only the vertices of grinding scratches, which for blade $a$ (Fig. 3a) extends to a width of about $400 \mu \mathrm{m}$.

In Fig. 5 grinding scratches can be seen, not worn out from the rake surface, up to a few microns distance to the cutting edge, with a large chipping on the right side. Lack of corrosion mosaic as well as the polished rake surface indicate the absence of TCCR during cutting of Scots pine wood using cemented carbide blade $\mathrm{KCr} 08$.

In the case of blade $b$ (Fig. 4), the zone of corrosion mosaic abruptly passes into the polished zone, but the visible features of grinding scratches extend to a width of more than $250 \mu \mathrm{m}$. The WC grain sized about $2 \mu \mathrm{m}$, can be distinguished in Fig. 6. Due to the fact that the largest size of corrosion mosaic reached $60 \mu \mathrm{m}$, it can be concluded that the TCCR attacked not only a binder of the tool material but also the $\mathrm{WC}$ grains. This observation points to a completely different mechanism of degradation of the 
Fig. 6 Cutting edge worn zone of blade $a$, SEM image in chemical contrast
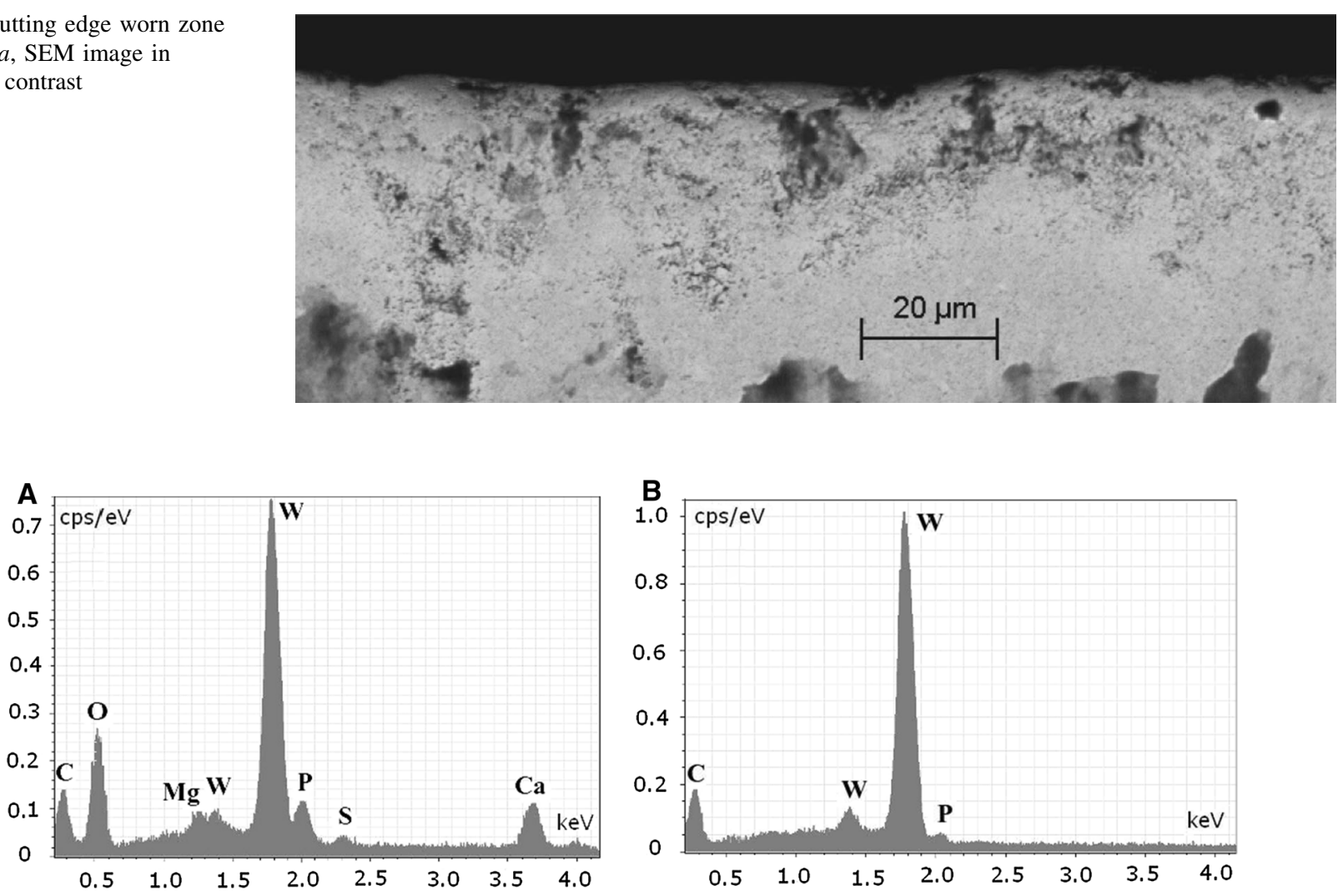

Fig. 7 EDS semi-quantitative analysis of the worn zone of blade $a$ : a darker (Fig. 6); b lighter (Fig. 6)

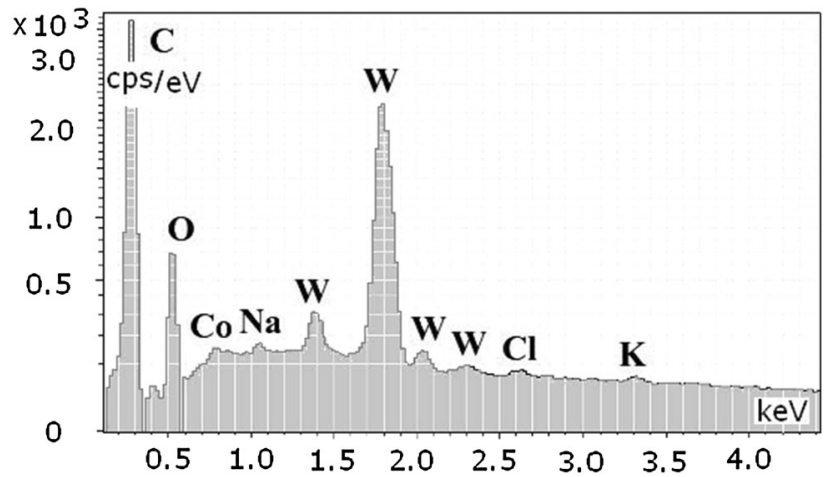

Fig. 8 EDS semi-quantitative analysis of the cutting edge worn zone of blade $a$

tool material in comparison to the mechanism described in literature for cutting of wood-based materials (Porankiewicz 2011).

Figure 7a shows the EDS spectrum obtained for the darker area (in the cavities). In this area, tungsten (W) and carbon (C) can be seen, which comes from cemented carbide. The presence of oxygen $(\mathrm{O})$, calcium $(\mathrm{Ca})$ and less phosphorus $(\mathrm{P})$, magnesium $(\mathrm{Mg})$ and negligible small amount of sulphur (S), can be associated with the accumulation of organic matter after thermal degradation of the material machined. In lighter areas (Fig. 7b), apparently cleaned from accumulations, the $\mathrm{W}$ and $\mathrm{C}$ are visible with negligible small content of $P$.

In Fig. 8, very high peaks of $\mathrm{W}, \mathrm{C}$ and $\mathrm{O}$ as well as negligible small amounts of sodium $(\mathrm{Na})$, chlorine $(\mathrm{Cl})$ and potassium $(\mathrm{K})$, derived from another worn zone of the cutting edge than in Fig. 7 can be seen. In this figure, the presence of cobalt (Co) was observed, which comes from binder of cemented carbide. Other components of the binder in cemented carbide $\mathrm{KCr} 08$ were not detected in the probe. The contents of $\mathrm{Na}, \mathrm{Cl}$ and $\mathrm{K}$ are presumed to be residues of thermal degradation of the work material. Because of semi-quantitative EDS analysis the low content of elements must be taken as an approximation.

The results of semi-quantitative analysis of EDS, indicating the presence of $\mathrm{Cl}, \mathrm{S}$ and $\mathrm{P}$ must not constitute grounds for believing in the existence of specific corrosion mechanisms such as halogenation or sulphidation (Porankiewicz 2002, 2003a; Porankiewicz and Chamot 2005) as was done in several published works (Reid et al. 1991; Stewart 1992). In order to explain the mechanism of observed symptoms of TCCR, causing extensive wear on the rake face, $\mathrm{X}$-ray photoelectron spectroscopy (XPS), an advanced surface analytical technique, has to be used. 

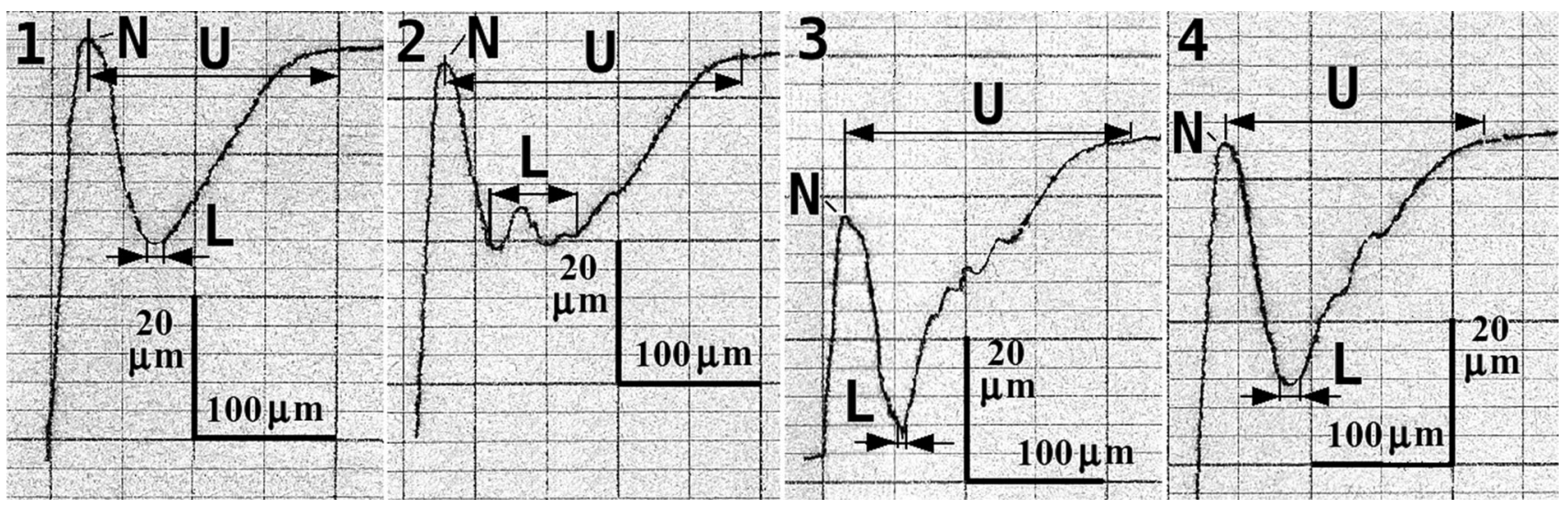

Fig. 9 Stylus transverse section of recesses on the rake face of blade $a ; N$ nose; $U$ upper zone; $L$ lower zone

Table 1 Results of measurements of the cutting edge of blade $a$ worn zone $(\mu \mathrm{m})$ on the basis of profiles shown in Fig. 9

\begin{tabular}{llllll}
\hline Cutting edge blade $a$ no. & 1 & 2 & 3 & 4 & Average \\
\hline $\begin{array}{l}\text { Width of the recess in the upper } \\
\text { zone (U, Fig. 9) }\end{array}$ & 150 & 190 & 160 & 170 & 168 \\
Width of the recess in the lower & 15 & 70 & 15 & 15 & 29 \\
$\quad$ zone (L, Fig. 9) & 28 & 25 & 38 & 36 & 32 \\
$\begin{array}{l}\text { Depth of the recess } \\
\text { Upper width of the nose (N, }\end{array}$ & 15 & 10 & 20 & 10 & 14 \\
$\quad$ Fig. 9) & & & & & \\
Bottom width of the nose (N, & 60 & 43 & 53 & 60 & 54 \\
$\quad$ Fig. 9) & & & & & \\
Height of nose & 28 & 25 & 29 & 34 & 29 \\
\hline
\end{tabular}

Figure 9 shows stylus transverse profiles of worn zones of the four edges. From this figure it can be seen that the recesses have different sizes, as illustrated by the results of measurements summarized in Table 1. At the bottom of the recess on the rake face of Fig. 9-2 a protrusion can be seen, suggesting a presumable change in feed speed $v_{f}$ during its life cycle. The recess from the left side of the protrusion can presumably be associated with lower feed speed $v_{f}$, which corresponds to the lower chip thickness $a_{p}$, and therefore shorter contact with the rake face. The recess from the right side of the protrusion can presumably be associated with larger feed speed $v_{f}$ which corresponds to the larger chip thickness $a_{p}$ and therefore longer contact with the rake face.

Profiles Fig. 9-1, 3, 4 exhibit roughness believed to be associated with the corrosion mosaic, indicating that the deepest recess of corrosion mosaics can reach about $2 \mu \mathrm{m}$. The mean values of upper and lower width of the recesses for four blades amounted to $168 \mu \mathrm{m}$ and $29 \mu \mathrm{m}$, respectively. The average depth of the recess was $32 \mu \mathrm{m}$. The average width of the top and bottom part of the nose for four blades amounted to 14 and $54 \mu \mathrm{m}$, respectively. The average height of the nose was $29 \mu \mathrm{m}$.

Results of TGA of the hardened and cured PVA-based modified adhesive, shown in Fig. 10a, indicate that the temperature of the thermal degradation of the adhesive tested is higher than the degradation temperature of PVA glue together with cobalt (Fig. 10b) and iron (Fig. 10c).

The application of TGA for the evaluation of TCCR between powdered components of tool material and material machined was proven as useful in the case of milling of wood and secondary wood products (Porankiewicz 2011).

PVA-based adhesive presumably decomposes and reacts to acetic acid at temperatures of $240-265{ }^{\circ} \mathrm{C}$. Maximum degradation temperature is $360{ }^{\circ} \mathrm{C}$. Figures $10 \mathrm{~b}$ and 10c indicate that the products of thermal degradation of the adhesive tested, presumably acetic acid, generated two corrosion peaks respectively in cobalt-a binder in the sintered carbide, and in iron. The first corrosion peak for cobalt lays in a temperature range from approximately 280-350 ${ }^{\circ} \mathrm{C}$, with a maximum at $330{ }^{\circ} \mathrm{C}$. The second corrosion peak for cobalt lays in a temperature range from about $550{ }^{\circ} \mathrm{C}$ to about $650{ }^{\circ} \mathrm{C}$, with a maximum at $600{ }^{\circ} \mathrm{C}$. In this temperature range a sudden increase in the intensity of corrosion of Co is assumed, resulting in a significant (as high as $12 \%$ ) increase in mass. The height and width of the second corrosion peak is much greater than any value previously published in literature (Porankiewicz 2002, 2003a, 2003b, 2006; Porankiewicz et al. 2005). This phase of the TGA analysis indicates the existence of an intensive process of corrosion, with increase in mass as high as $8.7 \%$, within a time of $1.2 \mathrm{~min}$.

The first corrosion peak for $\mathrm{Fe}$ lays in a temperature range of approximately $214-231{ }^{\circ} \mathrm{C}$, with a maximum at $224{ }^{\circ} \mathrm{C}$, the second in a temperature range from about $297{ }^{\circ} \mathrm{C}$ to about $357^{\circ} \mathrm{C}$ with a maximum at $334^{\circ} \mathrm{C}$. 
Fig. 10 TGA (TG and dTG) plot for: a hardened and cured PVA based, modified, glue; b Co together with glue, $\mathbf{c ~ F e}$ together with glue; corrosion peaks are dotted
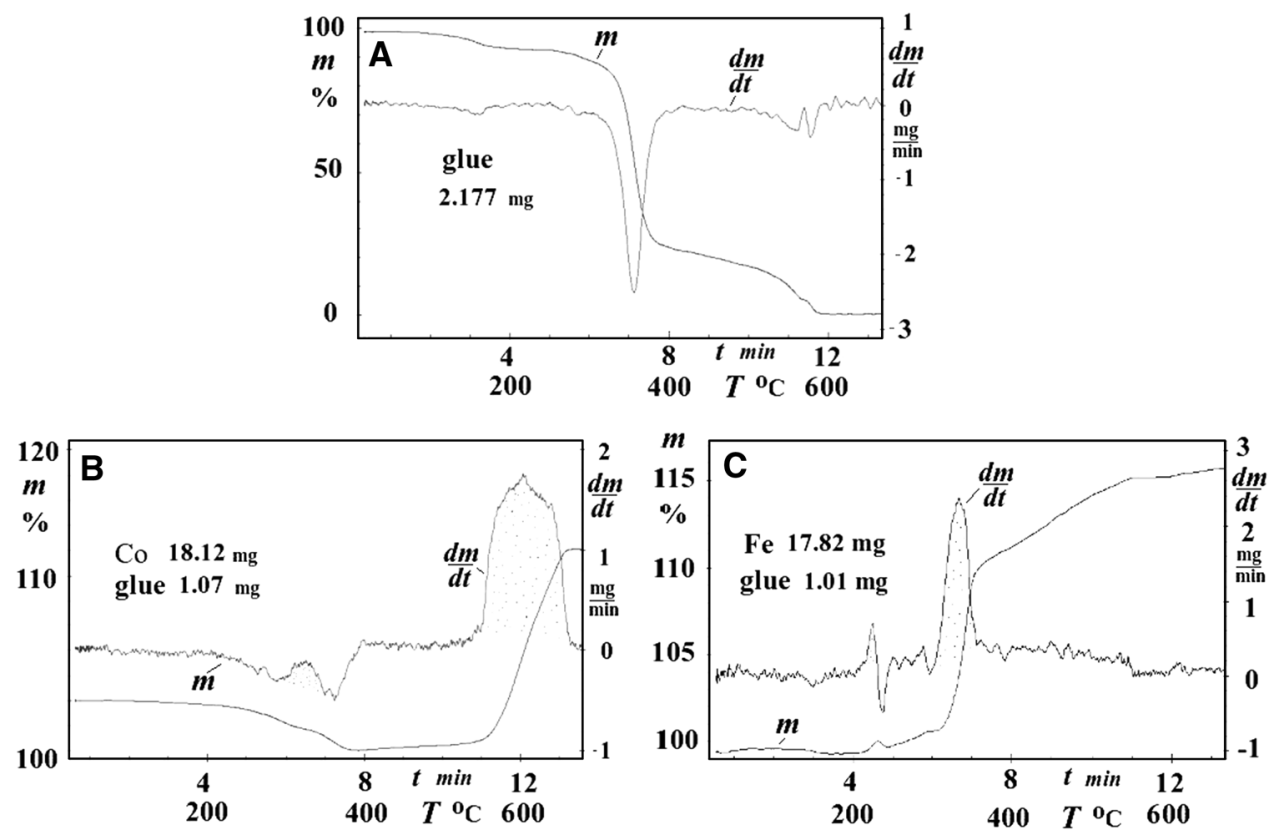

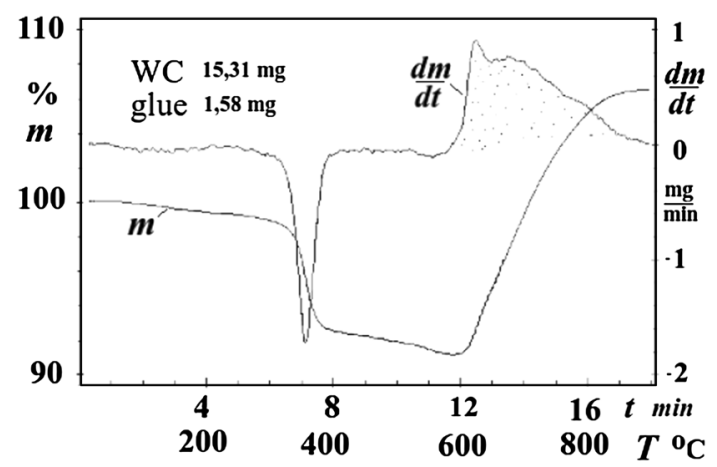

Fig. 11 TGA plot for WC grains together with modified, PVAbased, hardened and cured glue; corrosion peak is dotted

Due to the low chip pressure on the rake face, it can be presumed that in the case of cobalt binder, the first corrosion peak can be associated with observed intense wear, while in the case of $\mathrm{Fe}$ probably both peaks.

The corrosion peak for $\mathrm{Fe}$ is about three times shorter than in the case of Co. This explains why it was unsuccessful to use the HSS steel, an iron based tool material, for milling of Scots pine wood glued with PVA-based modified glue.

Figure 11 shows that the presence of WC did not affect the temperature of maximum degradation of the tested adhesive. At a temperature of $630^{\circ} \mathrm{C}$, visible corrosion peak of WC grains confirm the observations of the microscopy methods, suggesting that the TCCR affect the two basic corrosion reactions of the binder in the sintered carbide in contact with the modified PVA—-based adhesive thermal degradation products.
In the case of WC grains, second component of sintered carbide, no mass decrease can be seen in Fig. 11, what contradicts the hypothesis on sublimation of the WC grains in examined conditions (Reid et al.1991; Stewart 1992).

It has to be noted that the change of the form of perpendicular cross-section of worn cutting edge zone, together with evidenced acceleration of the cutting edge wearing during milling of wood laminated with PVAbased, modified glue contradicts the hypothesis on similarity of the wearing process when machining wood based materials with blades of cemented carbide tool material (Fischer 1997).

\section{Conclusion}

1. The worn zone of sintered carbide edges, after milling around $6,000 \mathrm{~m}$ of the feed path of laminated wood of Scots pine glued with PVA-based, modified adhesive, can be described quantitatively by the following parameters: width of the upper part of the recess, width of lower part of the recess, depth of the recess, width of bottom part of the nose, height of the nose, as large as $168,29,32,54$ and $29 \mu \mathrm{m}$, respectively.

2. The mechanism of accelerated wear of the cemented carbide cutting edge is of a different nature than those described previously in literature, when machining wood-based materials.

3. Intensive TCCR attacked not only a binder of the tool material, but also the WC grains, thus the corrosion mosaic sizes in the edge wear (recess) are repeatedly 
larger than the sizes of individual WC grains of $\mathrm{KCr} 08$ sintered carbide tool material.

4. Thermal gravimetric analysis of cobalt, binder in the sintered carbide, together with hardened, cured, powdered PVA-based, modified adhesive, indicates the intense TCCR process in temperature ranges: 280-350 ${ }^{\circ} \mathrm{C}$ and $550-650{ }^{\circ} \mathrm{C}$.

Acknowledgments The authors would like to thank Dr. E. Chamot for valuable help with the TGA results analysis.

Open Access This article is distributed under the terms of the Creative Commons Attribution License which permits any use, distribution, and reproduction in any medium, provided the original author(s) and the source are credited.

\section{References}

Cristóvão L, Grönlund A, Ekevad M, Sitoe R, Marklund B. (2009) Brittleness of cutting tools when cutting Ironwood. Proc 19th Int Wood Mach. Sem, Nanjing, China: 253-259

Cristóvão L, Grönlund A, Ekevad M, Sitoe R (2011) Tool wear for some lesser-known tropical wood species. Wood Mat Sci and Eng 6(3):155-161

Fischer R (1997) A way to observe and to calculate edge wearing in cutting wood materials. Proc 13th Int Wood Mach Sem, Vancouver, Canada: 631-640

Grube AE (1967) Derevorežûsie instrumenty (Wood cutting tools) Les prom, Moskva, Russia
Klamecki B (1967) A review of wood cutting tool wear literature. Holz Roh- Werkst 37:265-276

Porankiewicz B (2002) Tribochemical reactions of cutting-edge material during secondary wood-products cutting. Tribol Lett 13:141-145

Porankiewicz B (2003a) Tępienie się ostrzy i jakość przedmiotu obrabianego w skrawaniu płyt wiórowych (Cutting edge wearing and machining quality when miling particle boards). Printing House of Agricultural University of Poznań, Pol, Habilit. works, 341

Porankiewicz B (2003b) A method to evaluate the chemical properties of particleboard to anticipate and minimize cutting tool wear. Wood Sci Technol 37:47-58

Porankiewicz B (2006) Theoretical simulation of cutting edge wearing when secondary wood products cutting. Wood Sci Technol 40:107-117

Porankiewicz B (2011) Wearing Mechanisms Contributing to Reduced Tool Life after Wood and Secondary Wood Products Machining. In: Davim JP (ed) Wood machining. ISTE Ltd., London, and Wiley, Hoboken, pp 115-155

Porankiewicz B, Chamot E (2005) Tribochemical reactions of steel in cutting edge material during secondary wood products cutting. Tribol Lett 19:73-82

Porankiewicz B, Sandak J, Tanaka C (2005) Factors influencing steel tool wear when milling wood. Wood Sci Technol 39:225-234

Reid AS, Stewart HA, Rapp RA (1991) High temperature reactions of tungsten carbide-cobalt tool material with MDF. For Prod J 11(12):12-18

Staniszewski J, Porankiewicz B (1978) Kryteria i metody oceny stępienia nrzędzi skrawających do obróbki drewna (Criteria and blunting assessment methods of wood cutting tools). Print. House of Agricultural University of Poznań, Pol

Stewart HA (1992) High temperature halogenation of tungsten carbide cobalt tool material when machining MDF. For Prod J 10:25-31 